\title{
The effectivity of periprostatic nerve blockade for the pain control during transrectal ultrasound guided prostate biopsy
}

\author{
Alper Otunctemur ${ }^{1}$, Murat Dursun ${ }^{1}$, Huseyin Besiroglu ${ }^{1}$, Emre Can Polat ${ }^{2}$, \\ Suleyman Sami Cakir ${ }^{1}$, Emin Ozbek ${ }^{1}$, Tahir Karadeniz ${ }^{1}$ \\ ${ }^{1}$ Okmeydani Training and Research Hospital, Department of Urology, Istanbul, Turkey; \\ ${ }^{2}$ Balikligol State Hospital, Department of Urology, Sanliurfa, Turkey.
}

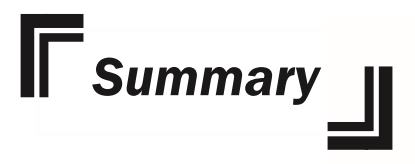

Aim: Transrectal ultrasound (TRUS) guided prostete biopsy is accepted as a standard procedure in the diagnosis of prostate cancer. Many different protocoles are applied to reduce the pain during the process. In this study we aimed to the comparison of two procedure with intrarectal lidocaine gel and periprostatice nerve blockade respectivesy by TRUS. ly in addition to perianal intrarectal lidocaine gel on the pain control in prostate biopMethods: 473 patients who underwent prostate biopsy guided TRUS between 2008-2012 were included in the study. 10-point linear visual analog pain scale(VAS) was used to evaluate the pain during biopsy. The patients were divided into two groups according to anesthesia procedure. In Group 1, there were 159 patients who had perianal-intrarectal lidocaine gel, in Group 2 there were 314 patients who had periprostatic nerve blockade in addition to intrarectal lidocain gel. The pain about probe manipulation was aseesed by VAS-1 and during the biopsy needle entries was evaluated by VAS-2. Results were compared with Mann-Whitney $U$ and Pearson chi-square test.

Results: Mean VAS-2 scores in Group 1 and Group 2 were $4.54 \pm 1.02$ and $2.06 \pm 0.79$ respectively. The pain score was determined significantly lower in the Group $2(p=0.001)$. In both groups there was no significant difference in VAS-1 scores, patient's age, prostate volume, complication rate and PSA level.

Conclusion: The combination of periprostatic nerve blockade and intrarectal lidocain gel provides a more meaningful pain relief compared to group of patients undergoing intrarectal lidocaine gel.

KEY WORDS: Transrectal prostete biopsy; Visual analog scale; Lidocaine; Periprostatic nerve blockade.

\section{INTRODUCTION}

Prostate cancer ( $\mathrm{PCa}$ ) is one of the most common cancers in men, with about 700,000 patients diagnosed worldwide each year (1). This figure is closely related to the development of early PCa detection programmes, which are based on an increased public awareness about this type of cancer, prostate-specific antigen screening efforts, and the improvement of systematic transrectal ultrasound (TRUS)-guided prostate biopsy (PBx) techniques. PBx has evolved from the digitally guided $\mathrm{PBx}$ technique, described by Astraldi (2) in 1937, to the standard sextant method, described by Hodge et al. (3) in 1989. Transrectal ultrasound guided prostete biopsy (TRUS-BX) is accepted as a standard procedure in the diagnosis of prostate cancer. Having established that the prostate spesific antigen (PSA) could be a useful marker for detection of prostatic cancer there has been a significant increase in the number of biopsies (4). However most of patients undergoing TRUS-BX have discomfort and \% 20 of these patients experienced severe pain about the procedure $(3,5)$.

Altough TRUS-BX is a standard common procedure there 
is no certain protocol or guideline for the preparation of the patient and need for analgesia and the technique used for administration $(3,5)$.

There are many different approaches to reduce the pain and enhance the patients adaptation to the procedure. There is no concensus about which method to use but the patient's consciousness, prior history about anorectal diseases, pain threshold of the patient, biopsy experience, socio-cultural level are important factors for the decision. The use of periprostatic nerve blockade (PPNB) had been introduced as early as 1996 (6) for minimizing prostatic biopsy pain with lignocaine local anaesthesia. Many studies evaluated and conclusively proved the benefit of PPNB (7-9).

In this study, we evaulated the pain control in patients who have TRUS-BX for detection prostate cancer, using PPNB for anaesthesia. We compared the efficacy of periprostatic nerve blockage with intrarectal gel instillation and just perianal intrarectal gel instillation during TRUS-guided prostate biopsy.

\section{MATERIALS AND METHOdS}

473 men who underwent ultrasound guided prostate biopsy from 2009 to 2012, were enrolled in this study. Increased prostate speific antigen (PSA), abnormal digital rectal examination findings and serum PSA levels higher than $2.5 \mathrm{ng} / \mathrm{ml}$ were the inclusion criterias. The patients were divided into two groups: in group 1 (159 patients) biopsies were performed after administering perianal intrarectal lidocain gel and in group 2 (314 patients) periprostatic nerve blockade was performed in addition to perianal intrarectal lidocain gel. Injections were delivered at the angle between the seminal vesicle and prostate on each side using $5 \mathrm{cc}$ of $2 \%$ lidocain. Exclusion criterias are as follows: bleeding diathesis and/or use of anticoagulant; anorectal diseases such as hemorrhoids, anal fissures, anal surgery; acute prostatitis; pelvic pain syndrome; history of lidocaine allergies; inability to rate a visual analog scale (VAS).

All patients receieved standard antibiotic prophylaxis with
$500 \mathrm{mg}$ of ciprofloxacin starting two days before and at least five days after the procedure. Bowel preparation was made with two fleet enema, one of them at previous night and the other one two hours before the procedure.

After giving detailed information and obtaining consent form, the patients were taken to the table on the lateral decubit position. TRUS was performed using a $6.5-\mathrm{MHz}$ transrectal probe. The prostate volume was calculated using both sagittal and transverse plans. Ten point linear visual analog scale (VAS) was used to determine the degree of the pain during transrectal ultrasound guided prostate biopsy. The pain arising from the probe input and manipulation (VAS-1) and the pain caused by the needle while taking biopsies from prostate (VAS-2) were assesed. All patients were observed for two hours for any complications such as rectal bleeding, hematuria, voiding difficulty and fever. Differences in the age, PSA levels, prostate volume, VAS scores were compared between two different anestethic practice groups. The comparisons about age, prostate volume and pain scores between two groups were applied using Mann-Whitney U test. Complication rates were examined with the Pearson chi-square test.

\section{RESULTS}

The mean ages were not statisticially different between two groups: $65.2 \pm 8.3$ for group $1,66.1 \pm 7.7$ for group 2. Mean PSA levels, prostate volumes and complication rates were similar and there was no statistically differences between the groups (Table 1). A critical status did not develop with respect to complications. The mean PSA levels were similar in group $1(15.5 \pm 23.1)$ and in group $2(11.9 \pm 13.6 \mathrm{ng} / \mathrm{ml})$.

The only statistically significant difference was determined in VAS-2 score between two groups. Mean pain score caused by the needle while taking biopsies from prostate (VAS-2) was lower in group 2 than in group 1. Mean VAS-2 scores were $4.54 \pm 1.02$ in group 1 and 2.06 \pm 0.79 in group 2 , respectively. There was no meaningful difference between the two groups of VAS-1 score which shows the pain about probe manipulation (Table 2).

Table 1.

Data of the patients in group 1 and group 2.

\begin{tabular}{|l|c|c|c|}
\hline Number of patients & Group 1 & Group 2 & P value \\
\hline Age $($ years $)$ & 159 & 314 & 0.405 \\
\hline PSA $(\mathrm{ng} / \mathrm{ml})$ & $65.2 \pm 8.3$ & $66.1 \pm 7.7$ & 0.331 \\
\hline Prostate volume $(\mathrm{ml})$ & $15.5 \pm 23.1$ & $11.9 \pm 13.6$ & 0.07 \\
\hline Complication rate $(\mathrm{n}, \%)$ & $60.3 \pm 24$ & $65.3 \pm 26.5$ & 0.1969 \\
\hline
\end{tabular}

Table 2.

The statistical data of VAS scores in the two groups.

\begin{tabular}{|l|c|c|c|}
\hline & Group 1 & Group 2 & P value \\
\hline Pain score (VAS1) & $2.19 \pm 0.9$ & $2.18 \pm 0.9$ & 0.904 \\
\hline Pain score (VAS2) & $4.54 \pm 1.02$ & $2.06 \pm 0.79$ & 0.001 \\
\hline
\end{tabular}




\section{Discussion}

Ultrasound guided prostate biopsy is a standard method used to detect prostate cancer. Pain during TRUS-BX is an important problem that is associated with the patient tolerance about procedure (5, 10-12). Pain mainly depends on two factors: anal discomfort due to the probe insertion and manipulation of the probe and the insertion of the needle through prostate capsule.

Periprostatic nerve blockage was firstly defined by Nash et al. in 1996 and it is a good choice to reduce the pain (6). In this study it was suggested to inject at the junction of the base of the prostate and seminal vesicles. These findings were similarly confirmed by Pareek et al. (9). There are many studies demonstrating that periprostatic nerve blockade is better than plasebo (13-21).

Recently new methods are being tested in various studies. In a study with 430 patients, acetaminophen and EMLA cream with intravenous injection of tramadol were found safe, easy, and effective methods of controlling pain during the procedure (18). In some studies midazolam was considered to be a suitable anesthetic during prostate biopsy $(17,20,21)$. The application of perianal intrarectal gel and cream provides a good pain relief caused by probe manipulation $(14,23,24)$. In the other hand, there are some studies showing that lidocaine gel did not diminish the sensation of pain $(16,25,26)$. Lidocaine suppositories are found an easyto-use and cheap method of local analgesia, with acceptable results (27). In a study published in 2011 by Skriapas et al., the use of topical lidocaine gel and glyceryl trinitrate ointment (GTN) as an adjunct to periprostatic anesthesia to reduce anal pain and discomfort due to probe insertion was found very effective and safe (28). In the other study lidocaine spray was found to provide significantly better pain control than cream and anaesthetic gel (29). Furthermore there are some studies comparing different anesthetic substances for pain relief. In a study by Olmez et al., tramadol and lornoxicam were used for pain reduction and tramadol was found to be more effective (30). Hirsh et al. had similar findings about tramadol in their study (31).

In our study, pain scores related to probe manipulation was similar between two groups but there was a very significant difference between the pain score caused by the needle used to take biopsy cores. It was shown that periprostatic nerve blockade is a very good choice for pain control and compliance of the patient to the procedure although it is not effective for anorectal discomfort caused by the probe. We recommend the use of perianal intrarectal lidocain gel and periprostatic nerve blockade combination in TRUS-guided prostate biopsises. This combination is effective, cheap, safe and easy to perform.

\section{REFERENCES}

1. Parkin DM, Bray F, Ferlay J, Pisani P. Global cancer statistics, 2002. CA Cancer J Clin. 2005; 55:74-108.

2. Astraldi A. Diagnosis of cancer of the prostate: biopsy by rectal route. Urol Cutaneous Rev. 1937; 41:421-422.

3. Hodge KK, McNeal JE, Terris MK, Stamey TA. Random systematic versus directed ultrasound guided transrectal core biopsies of the prostate. J Urol. 1989; 142:71-4.
4. Wang MC, Papsidero LD, Kuriyama M. Prostate antigen: a new potential marker for prostatic cancer. Prostate. 1981; 2:89-96.

5. Clements R, Aideyan OU, Griffiths GJ, Peeling WB. Side effects and patient acceptability of transrectal biopsy of the prostate. Clin Radiol. 1993; 47:125-6.

6. Nash PA, Bruce JE, Indudhara R, Shinohara K. Transrectal ultrasound guided prostatic nevre blockade eases systemic needle biopsy of the prostate. J Urol. 1996; 155:607-9.

7. Soloway MS, Obek C. Periprostatic local anaesthesia before ultrasound guided prostate biopsy. J Urol 2000; 163:172-3.

8. Alavi AS, Soloway MS, Vaidya A, et al. Local anaesthesia for ultrasound guided prostate biopsy: a prospective trial comparing 2 methods. J Urol. 2001; 166:1343-5.

9. Pareek G, Armenaskas NA, Fracchia JA. Periprostatic nerve blockade for transrectal ultrasound guided biopsy of the prostate: a randomized, double-blind, placebo controlled study. J Urol. 2001; 166:894-7.

10. Irani J, Fournier F, Bon D, et al. Patient tolerance of transrectal ultrasound-guided biopsy of the prostate. Br J Urol. 1997; 79:608-10.

11. Crundwell MC, Cooke PW, Wallace DM. Patients' tolerance of transrectal ultrasound-guided prostatic biopsy: an audit of 104 cases. BJU Int. 1999; 83:792-5.

12. Krishna NS, Kumar PM, Morrison L. Patients' tolerance of transrectal ultrasound-guided prostatic biopsy: an audit of 104 cases. BJU Int. 1999; 84:890.

13. Jones JS, Ulchaker JC, Nelson D, et al. Periprostatic local anesthesia eliminates pain of office-based transrectal prostate biopsy. Prostate Cancer Prostatic Dis. 2003; 6:53-5.

14. Skriapas K, Konstandinidis C, Samarinas M, et al. Pain level and anal discomfort during transrectal ultrasound for guided prostate biopsy. Does intrarectal administration of local anesthetic before periprostatic anesthesia makes any difference? Minerva Urol Nefrol. 2009; 61:137-42.

15. Lynn NN, Collins GN, Brown SC, O'Reilly PH. Periprostatic nerve block gives better analgesia for prostatic biopsy. BJU Int. 2002; 90:424-6.

16. Leung SY, Wong BB, Cheung MC, et al. Intrarectal administration of lidocaine gel versus plain lubricant gel for pain control during transrectal ultrasound-guided extensive 10-core prostate biopsy in Hong Kong Chinese population: prospective double-blind randomised controlled trial. Hong Kong Med J. 2006; 12:103-7.

17. Shrimali P, Bhandari Y, Kharbanda S, et al. Transrectal ultrasound-guided prostatic biopsy: midazolam, the ideal analgesic. Urol Int. 2009; 83:333-6.

18. Kim S, et al. Effect of Oral Administration of Acetaminophen and Topical Application of EMLA on Pain during Transrectal Ultrasound-Guided Prostate Biopsy. Korean J Urol. 2011; 52:452-6.

19. Saad F, Yoon BI, Kim SJ, et al. A prospective randomized trial comparing lidocaine and lubricating gel on pain level in patients undergoing transrectal ultrasound prostate biopsy. Can J Urol. 2002; 9:1592-4

20. Ozok HU, Sagnak L, Ates MA, et al. The efficiency of a sedative or analgesic supplement to periprostatic nerve blockage for pain control during transrectal ultrasound-guided prostate biopsy - a prospective, randomized, controlled, double blind study. Arch Med Sci. 2010; 6:787-92.

21. Izol V, Soyupak B, Seydaoglu G, et al. Three different techniques for administering analgesia during transrectal ultrasound-guided prostate biopsy: a comparative study. Int Braz J Urol. 2012; 38:122-8. 
22. Song JH, Doo SW, Yang WJ, et al. Value and Safety of Midazolam Anesthesia during Transrectal Ultrasound-Guided Prostate Biopsy. Korean J Urol. 2011; 52:216-20.

23. Alvarez-Mugica M, González Alvarez RC, Jalón Monzón A, et al. Tolerability and complications of ultrasound guided prostate biopsies with intrarectal lidocaine gel. Arch Esp Urol. 2007; 60:237-44.

24. Siddiqui EJ, Ali S, Koneru S. The rectal administration of lignocaine gel and periprostatic lignocaine infiltration during transrectal ultrasound-guided prostate biopsy provides effective analgesia. Ann R Coll Surg Engl 2006; 88:218-21.

25. Diaz Perez GA, Meza Montoya L, Morante Deza C, et al. Pain during transrectal ultrasound guided needle biopsy of the prostate: comparison of the use or not of lidocaine gel. Actas Urol Esp. 2009; 33:134-7.

26. Argüelles Salido E, Congregado Ruiz CB, Conde Sánchez JM, et al. Ultrasound guided transrectal prostatic biopsy and pain. Prospective randomized study comparing lubricant gel, lidocaine gel, and anesthetic blockage of the neurovascular bundles with 1\% lidocaine. Arch Esp Urol. 2008; 61:579-90.
27. Goluza E, Hudolin T, Kastelan Z, et al. Lidocaine suppository for transrectal ultrasound-guided biopsy of the prostate: a prospective, double-blind, randomized study. Urol Int. 2011; 86:315-9.

28. Skriapas K, Konstantinidis C, Samarinas M, et al. Comparison between lidocaine and glyceryl trinitrate ointment for perianalintrarectal local anesthesia before transrectal ultrasonographyguided prostate biopsy: a placebo-controlled trial. Urology. 2011; 77:905-8

29. Dell'Atti L, Daniele C. Lidocaine spray administration during transrectal ultrasound guided prostate biopsy modified the discomfort and pain of the procedure: results of a randomized clinical trial. Arch Ital Urol Androl. 2010; 82:125-7.

30. Olmez G, Kaya S, Aflay U, Sahin H. Comparison of lornoxicam versus tramadol analgesia for transrectal prostate biopsy: a randomized prospective study. Int Urol Nephrol. 2008; 40:341-4.

31. Hirsh I, Kaploun A, Faris G, et al. Tramadol improves patients' tolerance of transrectal ultrasound-guided prostate biopsy. Urology. 2007; 69:491-4.

\section{Correspondence}

Alper Otunctemur, MD

Murat Dursun, MD (Corresponding Author)

mrt_drsn@hotmail.com

Huseyin Besiroglu, MD

Suleyman Sami Cakir, MD

Emin Ozbek, MD

Tahir Karadeniz, MD

Okmeydani Training and Research Hospital, Department of Urology

34384, Darulaceze cad. No: 25 Sisli, Istanbul, Turkey

Emre Can Polat, $M D$

Balikligol State Hospital, Department of Urology, Sanliurfa, Turkey 